Article

\title{
Synthesis, Structural Features, and Catalytic Activity of an Iron(II) 3D Coordination Polymer Driven by an Ether-Bridged Pyridine-Dicarboxylate
}

\author{
Na Zhao ${ }^{1}$, Yu Li ${ }^{1}{ }^{1 *}$, Jinzhong Gu ${ }^{2}$, Marina V. Kirillova ${ }^{3}$ and Alexander M. Kirillov ${ }^{3,4, *(1)}$ \\ 1 Guangdong Research Center for Special Building Materials and Its Green Preparation Technology, Foshan \\ Research Center for Special Functional Building Materials and their Green Preparation Technology, \\ Guangdong Industry Polytechnic, Guangzhou 510300, China \\ 2 College of Chemistry and Chemical Engineering, Lanzhou University, Lanzhou 730000, China \\ 3 Centro de Química Estrutural, Instituto Superior Técnico, Universidade de Lisboa, Av. Rovisco Pais, \\ 1049-001 Lisbon, Portugal \\ 4 Research Institute of Chemistry, Peoples' Friendship University of Russia (RUDN University), \\ 6 Miklukho-Maklaya st., 117198 Moscow, Russia \\ * Correspondence: liyuletter@163.com (Y.L.); kirillov@tecnico.ulisboa.pt (A.M.K.); Tel.: +86-20-61230629; \\ $+351-218417178$
}

Received: 9 June 2019; Accepted: 18 July 2019; Published: 20 July 2019

\begin{abstract}
New iron(II) three-dimensional coordination polymer (3D CP), [Fe( $\left.\left.\mu_{3}-\mathrm{Hcpna}\right)_{2}\right]_{\mathrm{n}}(\mathbf{1})$, was assembled under hydrothermal conditions from 5-(4'-carboxyphenoxy)nicotinic acid $\left(\mathrm{H}_{2}\right.$ cpna) as a trifunctional organic $\mathrm{N}, \mathrm{O}$-building block. This stable microcrystalline $\mathrm{CP}$ was characterized by standard methods for coordination compounds in the solid state (infrared spectroscopy, elemental analysis, thermogravimetric analysis, powder and single-crystal X-ray diffraction). Structure and topology of 1 were examined and permitted an identification of a 3,6-connected framework of the $\mathbf{r t l}$ topological type. In addition, compound $\mathbf{1}$ acts as effective catalyst precursor for oxidative functionalization of alkanes (propane and cyclic $\mathrm{C}_{5}-\mathrm{C}_{8}$ alkanes) under homogeneous catalysis conditions, namely for the oxidation of saturated hydrocarbons with $\mathrm{H}_{2} \mathrm{O}_{2} / \mathrm{H}^{+}$system to produce ketones and alcohols, and for alkane carboxylation with $\mathrm{CO} / \mathrm{H}_{2} \mathrm{O} / \mathrm{S}_{2} \mathrm{O}_{8}{ }^{2-}$ system to obtain carboxylic acids. The influence of an acid promoter and substrate scope (propane and cyclic $\mathrm{C}_{5}-\mathrm{C}_{8}$ alkanes) were investigated.
\end{abstract}

Keywords: metal-organic frameworks; coordination polymers; iron; hydrothermal synthesis; crystal engineering; C-H functionalization; homogeneous catalysis; cycloalkanes; propane; oxidation; carboxylation

\section{Introduction}

Coordination polymers (CPs) are now very popular compounds because of their highly diverse and unusual structures and interesting applications in various areas, which range from separation and sorption of gases [1-3] to luminescent [4,5] and catalytic materials [6-8], as well as molecular magnets $[9,10]$ and sensors $[11,12]$. CPs are typically built from metal nodes and organic ligands such as polycarboxylic acids that act as spacers and/or linkers. Assembly and functional properties of CPs are usually affected by a diversity of parameters such as conditions of the synthesis, coordination preferences of metal nodes, as well as types of organic linkers or spacers [13-19].

The use of polycarboxylic acid ligands that combine different functional groups represents an interesting research direction for designing new types of coordination polymers or metal-organic frameworks (MOFs) [20-22]. Following our continuous interest in exploring new or poorly studied 
multicarboxylic acids for the design of CPs [23-30], in this work we selected a trifunctional nicotinic acid derivative, 5-(4'-carboxyphenoxy)nicotinic acid ( $\mathrm{H}_{2}$ cpna) as a main building block. Selection of $\mathrm{H}_{2}$ cpna can be justified by the following points. (1) This carboxylic acid can potentially act as a trifunctional ligand containing one phenyl and one pyridine ring which are connected by a gyrating $O$-ether functionality. (2) There are three different functional group classes (i.e., $\mathrm{N}$-pyridyl, $-\mathrm{COOH}$, $\mathrm{O}$-ether) in $\mathrm{H}_{2}$ cpna and six possible coordination sites. (3) $\mathrm{H}_{2}$ cpna is still barely investigated for synthesis of CPs or MOFs. In fact, a search of the Cambridge Structural Database shows that there are only several examples of $\mathrm{Zn}, \mathrm{Cu}, \mathrm{Ni}, \mathrm{Co}, \mathrm{Mn}, \mathrm{Cd}$, and $\mathrm{Pb}$ coordination polymers assembled from $\mathrm{H}_{2} \mathrm{Cpna}$; some of them revealed interesting catalytic [8], sensing [11], gas sorption [21], luminescent [11,27], and magnetic [27] properties. Notable examples include a 2D Co(II) CP [Co $\left(\mu_{3} \text {-cpna) }(\text { phen })\left(\mathrm{H}_{2} \mathrm{O}\right)\right]_{n} \cdot \mathrm{nH}_{2} \mathrm{O}$ \{phen, 1,10-phenanthroline\} applied as a heterogeneous catalyst for alcohol oxidation [8], a $\mathrm{Tb}^{3+}$-doped $3 \mathrm{D} \mathrm{Cu}(\mathrm{II}) \mathrm{MOF}\left[\mathrm{Cu}\left(\mu_{3} \text {-cpna }\right)_{2}\right]_{n}$ used as a luminescent probe for sensing $\mathrm{H}_{2} \mathrm{~S}$ [11], and a 2D porous framework $\left[\mathrm{Cu}\left(\mu_{3} \text {-cpna) }\left(\mathrm{Me}_{2} \mathrm{NH}\right)\right]_{n} \cdot n D M F \cdot \mathrm{nH}_{2} \mathrm{O}\{\mathrm{DMF}\right.$, dimethylformamide $\}$ with remarkable $\mathrm{CO}_{2}$ sorption behavior in addition to single-crystal to single-crystal transformation features [21]. Despite these examples, iron derivatives of $\mathrm{H}_{2}$ cpna remain virtually unknown.

Apart from this point, the selection of iron as a metal to construct a new coordination polymer is explained by its availability and high coordination versatility, as well as interesting redox chemistry that might be important for applications in catalysis. Thus, iron(II) sulfate $\left(\mathrm{FeSO}_{4} \cdot 7 \mathrm{H}_{2} \mathrm{O}\right)$ was explored as a low-cost and water-soluble iron(II) precursor for the hydrothermal synthesis of an $\mathrm{H}_{2}$ cpna-derived compound. On the other hand, the hydrothermal synthetic conditions were used to aid the crystallization of a product as single crystals in addition to other advantages such as use of water as green reaction medium and no need for work-up to purify and isolate the product [26].

In this study, we describe a hydrothermal generation, characterization, crystal structure, topological interpretation, thermal stability, as well as catalytic behavior of a new iron(II) coordination polymer assembled from 5-(4'-carboxyphenoxy)nicotinic acid. The obtained product $\left[\mathrm{Fe}\left(\mu_{3}-\mathrm{Hcpna}\right)_{2}\right]_{\mathrm{n}}(\mathbf{1})$ is the first $\mathrm{Fe}$ coordination compound assembled from $\mathrm{H}_{2}$ cpna. Besides, it also acts an efficient catalyst precursor for the oxidative functionalization of different saturated hydrocarbons under homogeneous conditions.

\section{Experimental}

\subsection{Materials and Physical Measurements}

Analytical reagent grade chemicals were applied. $\mathrm{H}_{2}$ cpna was acquired from a commercial supplier (Jinan Henghua Sci. \& Tec. Co., Ltd, http://www.chemhh.com, catalogue code: 120511H-1B, purity $98 \%$, CAS: 1777822-70-4). Elemental C, H, N analysis was run on an Elementar Vario EL elemental analyzer. Infrared (IR) spectra were obtained on a Bruker EQUINOX 55 spectrometer (KBr disks). TGA (thermogravimetric analysis) was carried out on a LINSEIS STA PT1600 thermal analyzer $\left(\mathrm{N}_{2}\right.$ atmosphere, $10{ }^{\circ} \mathrm{C} / \mathrm{min}$ heating rate). PXRD (powder X-ray diffraction) pattern was obtained on a Rigaku-Dmax 2400 diffractometer $(\mathrm{Cu}-\mathrm{K} \alpha$ radiation; $\lambda=1.54060 \AA$ ). UV-Vis absorption spectra were determined on a Cary 5000 UV-vis-NIR spectrophotometer. For catalytic tests, GC (gas chromatography) analyses were carried out using an Agilent Technologies 7820A series gas chromatograph (FID: flame ionization detector; carrier gas: He; capillary column: BP20/SGE).

\subsection{Synthesis of $\left[\mathrm{Fe}\left(\mu_{3}-\mathrm{Hcpna}\right)_{2}\right]_{n}$ (1)}

$\mathrm{FeSO}_{4} \cdot 7 \mathrm{H}_{2} \mathrm{O}(0.15 \mathrm{mmol}, 41.7 \mathrm{mg}), \mathrm{H}_{2}$ cpna $(0.3 \mathrm{mmol}, 77.7 \mathrm{mg}), \mathrm{NaOH}(0.3 \mathrm{mmol}, 12.0 \mathrm{mg})$, and water $(10 \mathrm{~mL})$ were combined in a Teflon-lined stainless-steel reactor $(25 \mathrm{~mL}$ volume $)$ and stirred for 15 min at ambient temperature. The reactor was then sealed, heated for 3 days at $160{ }^{\circ} \mathrm{C}$, and gradually cooled $\left(10^{\circ} \mathrm{C} / \mathrm{h}\right.$ rate) to ambient temperature. Yellow crystals (blocks) were manually isolated, washed with bidistilled water, and then air-dried to furnish compound 1. Yield: $55 \%$ (on the bases of $\mathrm{H}_{2} \mathrm{cpna}$ ). Calcd for $\mathrm{C}_{26} \mathrm{H}_{16} \mathrm{FeN}_{2} \mathrm{O}_{10}$ : C 54.57, H 2.82, N 4.90\%. Found: C 54.79, H 2.80, N 4.93\%. IR $\left(\mathrm{KBr}_{\mathrm{cm}}{ }^{-1}\right)$ : 
1646 s, 1605 m, 1579 m, 1511 w, 1455 w, 1398 s, 1304 m, 1273 s, 1242 w, 1206 m, 1164 m, 1112 w, 1050 w, 1014 w, 962 w, 895 w, 848 w, 785 w, 713 w, 693 w, 604 w, 547 w.

\subsection{X-ray Crystallography}

For 1, single-crystal X-ray data were collected using a Bruker APEX-II CCD diffractometer with a graphite-monochromated Mo $K_{\alpha}$ radiation $(\lambda=0.71073 \AA$, Bruker Corporation, Billerica, MA, USA). Semiempirical absorption corrections were performed with SADABS software (Bruker AXS, version 5.624, Madison, Wisconsin, USA). Structure of 1 was determined by direct methods, followed by a refinement (full-matrix least-squares on $F^{2}$ ) with SHELXS-97/SHELXL-97 [31,32]. Apart from $\mathrm{H}$ atoms, all other types of atoms underwent an anisotropic refinement (full-matrix least-squares on $F^{2}$ ). Hydrogen atoms (with an exception of $\mathrm{COOH}$ group) were positioned in calculated sites having fixed isotropic thermal parameters. These were considered in structure factor calculations at the final stage of full-matrix least-squares refinement. For $\mathrm{COOH}$ group, $\mathrm{H}$ atom of was found using difference maps, followed by its restriction to be at its parent oxygen atom. Crystal parameters for $\mathbf{1}$ are summarized in Table 1. Topological description of metal-organic net in $\mathbf{1}$ was performed following the concept of underlying (simplified) network [33]. This net was built [33] by reducing $\mu_{3}$-Hcpna ${ }^{-}$blocks to respective centroids, while their connections with iron(II) nodes were maintained [34]. CCDC-1906984 for $\mathbf{1}$ contains the supplementary crystallographic data.

Table 1. Crystal structure parameters for coordination polymer $\mathbf{1}$.

\begin{tabular}{|c|c|}
\hline Compound & 1 \\
\hline Chemical formula & $\mathrm{C}_{26} \mathrm{H}_{16} \mathrm{FeN}_{2} \mathrm{O}_{10}$ \\
\hline Molecular weight & 572.26 \\
\hline Crystal system & Monoclinic \\
\hline Space group & $P 2_{1} / n$ \\
\hline$a / \AA$ & $9.4673(7)$ \\
\hline$b / \AA$ & $9.2170(6)$ \\
\hline$c / \AA$ & $14.0358(9)$ \\
\hline$\alpha /\left(^{\circ}\right)$ & 90 \\
\hline$\beta /\left(^{\circ}\right)$ & $108.079(8)$ \\
\hline$\gamma /\left(^{\circ}\right)$ & 90 \\
\hline$V / \AA^{3}$ & $1164.30(15)$ \\
\hline Z & 2 \\
\hline$F(000)$ & 584 \\
\hline Crystal size/mm & $0.27 \times 0.25 \times 0.23$ \\
\hline$\theta$ Range for data collection & $3.770-25.049$ \\
\hline Limiting indices & $-9 \leq h \leq 11,-10 \leq k \leq 10,-16 \leq l \leq 10$ \\
\hline Reflections collected/unique $\left(R_{\text {int }}\right)$ & $4273 / 2053(0.0558)$ \\
\hline$D_{\mathrm{c}} /\left(\mathrm{Mg} \cdot \mathrm{cm}^{-3}\right)$ & 1.632 \\
\hline$\mu / \mathrm{mm}^{-1}$ & 0.715 \\
\hline Data/restraints/parameters & 2053/0/179 \\
\hline Goodness-of-fit on $F^{2}$ & 1.029 \\
\hline Final $R$ indices $[(I \geq 2 \sigma(I))] R_{1}, \mathrm{w} R_{2}$ & $0.0502,0.0890$ \\
\hline$R$ indices (all data) $R_{1}$, w $R_{2}$ & $0.0895,0.1084$ \\
\hline Largest diff. peak and hole $/\left(\mathrm{e} \cdot \AA^{-3}\right)$ & 0.329 and -0.376 \\
\hline
\end{tabular}

\subsection{Catalytic Oxidation of Cyclic Alkanes}

The reactions were carried out in glass reactors $\left(50 \mathrm{~mL}\right.$ volume, thermostated at $50{ }^{\circ} \mathrm{C}$, and equipped with a reflux condenser) under aerobic conditions and constant magnetic stirring; acetonitrile was used as solvent and added up to $2.5 \mathrm{~mL}$ of the total volume of the reaction mixture. Typical reaction procedure: catalyst precursor $1(0.005 \mathrm{mmol})$ was suspended in $\mathrm{CH}_{3} \mathrm{CN}$ and then an acid promoter $(0.015-0.1 \mathrm{mmol})$ and a gas chromatography (GC) internal standard $\left(\mathrm{CH}_{3} \mathrm{NO}_{2}, 250 \mu \mathrm{L}\right)$ were introduced. The oxidation reaction began on addition of cycloalkane $(1 \mathrm{mmol})$ and $\mathrm{H}_{2} \mathrm{O}_{2}(5 \mathrm{mmol}, 50 \%$ 
in water) and its progress was followed by taking small aliquots of the reaction mixture at different periods of time. Before GC analysis (internal standard method), each aliquot was treated with a small amount of solid triphenylphosphine that is necessary to reduce cycloalkyl hydroperoxides (primary products in the oxidation of cycloalkanes) and remaining hydrogen peroxide; the product yields are based on the GC data after the treatment with $\mathrm{PPh}_{3}$. Blank tests were performed and showed that the oxidation of cycloalkanes does not occur in the absence of Fe catalyst.

\subsection{Catalytic Oxidation of Propane}

The following reagents were combined in a stainless-steel reactor $(20.0 \mathrm{~mL}$ total volume): catalyst precursor 1 ( $0.005 \mathrm{mmol}$ ), solvent $\mathrm{CH}_{3} \mathrm{CN}$ (up to $2.5 \mathrm{~mL}$ of total volume of the reaction mixture), acid promoter (PCA, $0.015 \mathrm{mmol}$ or TFA, $0.1 \mathrm{mmol}$ ), $\mathrm{CH}_{3} \mathrm{NO}_{2}$ (GC internal standard, $250 \mu \mathrm{L}$ ), and $\mathrm{H}_{2} \mathrm{O}_{2}$ ( $5 \mathrm{mmol}, 50 \%$ in water). The reactor was then sealed, pressurized with $\mathrm{C}_{3} \mathrm{H}_{8}(1 \mathrm{~atm})$ and heated at $50{ }^{\circ} \mathrm{C}$ for $4 \mathrm{~h}$ under magnetic stirring. After cooling the reactor, it was degassed and the samples of the reaction mixtures were analyzed by GC (internal standard method). Before the analysis, the samples were treated with $\mathrm{PPh}_{3}$. Blank tests disclosed that the oxidation of propane does not occur in the absence of Fe catalyst.

\subsection{Catalytic Carboxylation of Alkanes}

Typical procedure: catalyst precursor $1(0.01 \mathrm{mmol}), \mathrm{CH}_{3} \mathrm{CN}(4.0 \mathrm{~mL}), \mathrm{H}_{2} \mathrm{O}(2.0 \mathrm{~mL})$, cycloalkane substrate $(1.0 \mathrm{mmol})$, and $\mathrm{K}_{2} \mathrm{~S}_{2} \mathrm{O}_{8}(1.50 \mathrm{mmol})$ were combined in a stainless-steel reactor $(20.0 \mathrm{~mL}$ total volume). It was sealed and flushed three times with carbon monoxide to remove air and then pressurized with $\mathrm{CO}(20 \mathrm{~atm})$. For carboxylation of $\mathrm{C}_{3} \mathrm{H}_{8}$, the reactor was first flushed and pressurized with the substrate $(1 \mathrm{~atm})$ and then $\mathrm{CO}$ was added. The reactor was heated at $50{ }^{\circ} \mathrm{C}$ for $4 \mathrm{~h}$ under magnetic stirring. After cooling the reactor, it was degassed and the reaction mixture was transferred to a glass flask. Diethyl ether $(9.0 \mathrm{~mL}$ ) and GC internal standard (cycloheptanone, $45 \mu \mathrm{L}$ ) were added (cyclohexanone was used as a GC standard in cycloheptane carboxylation). The obtained mixture was stirred for $10 \mathrm{~min}$ and then the aliquots were withdrawn from organic layer and analyzed by GC (internal standard method).

\section{Results and Discussion}

\subsection{Synthesis and Characterization}

The hydrothermal synthesis (at $160{ }^{\circ} \mathrm{C}$ for 3 days) using a mixture in water of iron(II) sulfate (FeSO $\left.{ }_{4} \cdot 7 \mathrm{H}_{2} \mathrm{O}\right), \mathrm{H}_{2}$ cpna (5-(4'-carboxyphenoxy)nicotinic acid) as a trifunctional organic block, and sodium hydroxide as a base resulted in a 3D coordination polymer formulated as $\left[\mathrm{Fe}\left(\mu_{3}-\mathrm{Hcpna}\right)_{2}\right]_{\mathrm{n}}(\mathbf{1})$. The molar ratio between $\mathrm{FeSO}_{4} \cdot 7 \mathrm{H}_{2} \mathrm{O}, \mathrm{H}_{2}$ cpna, $\mathrm{NaOH}$, and $\mathrm{H}_{2} \mathrm{O}$ was 1:2:2:3700, and the $\mathrm{pH}$ value of the initial reaction mixture was in the $4-5$ range. The compound 1 was isolated in a good yield as a crystalline solid (including single crystals of X-ray quality) and characterized by conventional techniques, which also include a single-crystal $\mathrm{X}$-ray diffraction. Product $\mathbf{1}$ is insoluble in any solvent and maintains its stability in e.g. $\mathrm{CH}_{3} \mathrm{CN} / \mathrm{H}_{2} \mathrm{O}$ medium at $60{ }^{\circ} \mathrm{C}$, as confirmed by powder X-ray diffraction (Figure S4, Supplementary Materials). In the IR spectrum of compound 1 (Figure S3, Supplementary Materials), the most characteristic, broad and intense bands of the carboxylate groups appear at 1605 and $1398 \mathrm{~cm}^{-1}$ and correspond to $v_{\text {as }}(\mathrm{COO})$ and $v_{\mathrm{s}}(\mathrm{COO})$ vibrations, respectively. Apart from these broad bands, there are also several minor shoulders or neighboring $v(\mathrm{COO} / \mathrm{COOH})$ bands centered at 1455, 1398, and $1304 \mathrm{~cm}^{-1}$. For $\mathrm{H}_{2}$ cpna, the strongest vibrations of carboxylic acid groups are observed at 1676 and $1305 \mathrm{~cm}^{-1}$ (Figure S2, Supplementary Materials). Different position of the main band maxima in $\mathbf{1}$ and $\mathrm{H}_{2}$ cpna indicates the coordination of carboxylic acid ligand to iron(II) centers in 1, as further supported by elemental and thermogravimetric analyses along with the PXRD and single-crystal X-ray diffraction data. 


\subsection{Description of Structural and Topological Features}

Product 1 possesses a 3D coordination polymer structure (Figure 1). Its asymmetric unit bears one $\mathrm{Fe}(\mathrm{II})$ atom (with a half occupancy) and one $\mu_{3}$-Hcpna $^{-}$block. The six-coordinate Fe1 atom displays the distorted $\left\{\mathrm{FeN}_{2} \mathrm{O}_{4}\right\}$ octahedral environment (Figure 1a and Figure S1). It is completed by two nitrogen and four carboxylate oxygen donors coming from six $\mu_{3}-\mathrm{Hcpna}^{-}$moieties. The $\mathrm{Fe}-\mathrm{O}$ [2.075(3)-2.183(3) $\AA$ ] and Fe-N [2.152(3) $\AA$ ] distances are typical for a present type of Fe(II) coordination compounds [35,36]. The Hcpna ${ }^{-}$ligand acts as a $\mu_{3}-\mathrm{N}, \mathrm{O}_{2}$-spacer (Scheme 1 ) with the $\mathrm{COOH}$ and $\mathrm{COO}^{-}$ groups adopting monodentate modes. The Hcpna- block is considerably bent showing a dihedral angle of $87.94^{\circ}$ between benzene and pyridyl functionalities, while a $\mathrm{C}-\mathrm{O}_{\text {ether }}-\mathrm{C}$ angle is $117.97^{\circ}$. The $\mu_{3}-\mathrm{N}, \mathrm{O}_{2}-\mathrm{Hcpna}^{-}$blocks multiply link neighboring $\mathrm{Fe}(\mathrm{II})$ nodes to form a 3D CP structure (Figure $1 \mathrm{~b}, \mathrm{c}$ ). Compound 1 shows no porosity, as confirmed by calculating an effective free volume of the crystal volume by PLATON; its unit cell contains no residual solvent accessible voids.

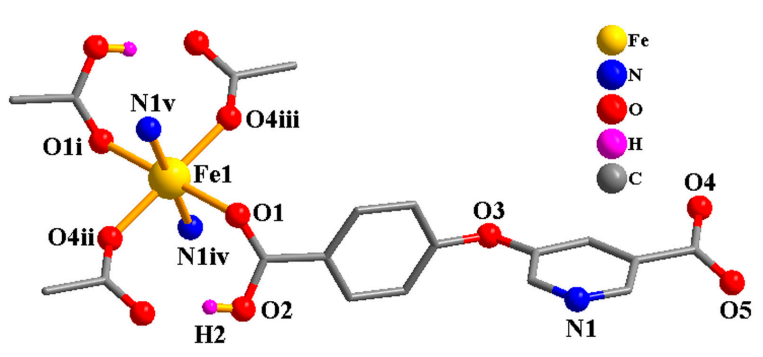

(a)

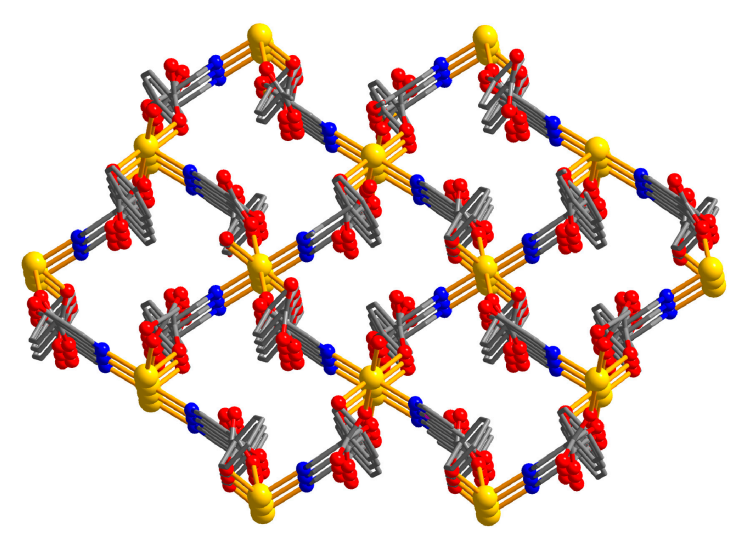

(c)

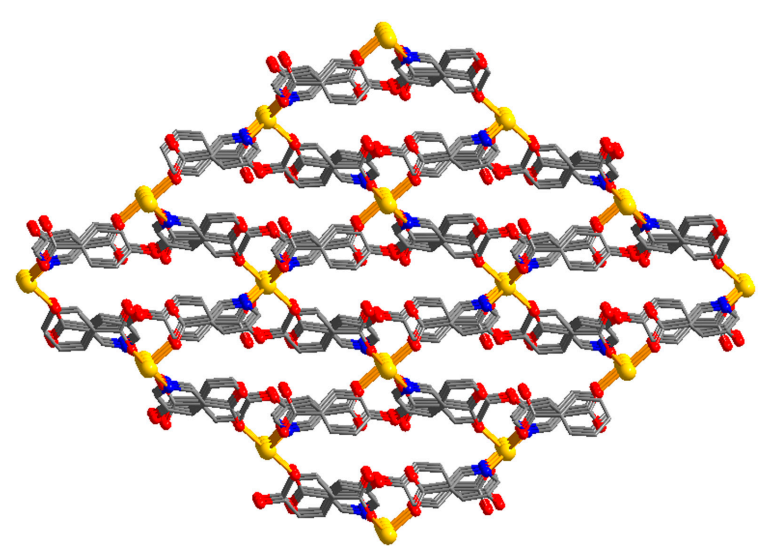

(b)

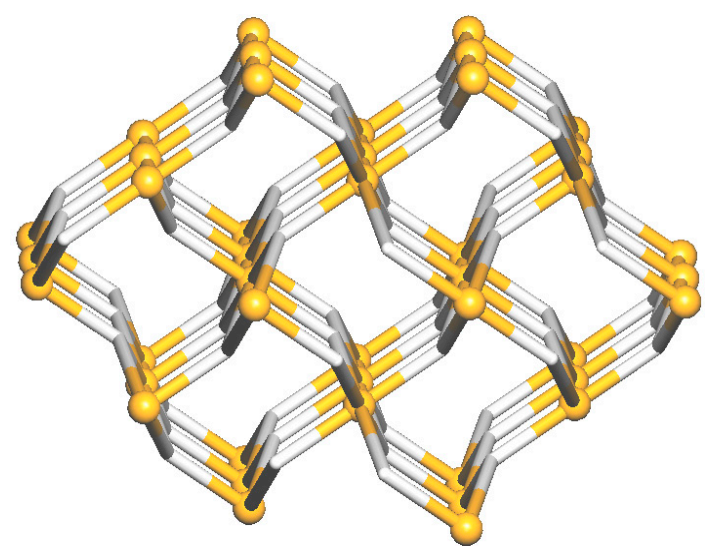

(d)

Figure 1. Different structural representations of 1. (a) Connectivity and coordination sphere of the Fe1 center; hydrogen atoms are not shown with an exception of $\mathrm{H}$ in $\mathrm{COOH}$. Symmetry operators: $\mathrm{i}=-x$ $+1,-y+1,-z ;$ ii $=x, y, z-1$; iii $=-x+1,-y+1,-z+1$; iv $=-x+1 / 2, y+1 / 2,-z+1 / 2 ; \mathrm{v}=x+1 / 2$, $-y+1 / 2, z-1 / 2$. (b,c) Three-dimensional metal-organic network along the $a$ and $c$ axis, respectively. (d) Topological view of a 3D coordination polymer displaying a 3,6-connected binodal underlying net of the rtl (rutile) topological type. View along the $c$ axis; colors: centroids of 3-connected $\mu_{3}-\mathrm{Hcpna}^{-}$ nodes (gray), 6-connected Fe1 nodes (orange balls). 


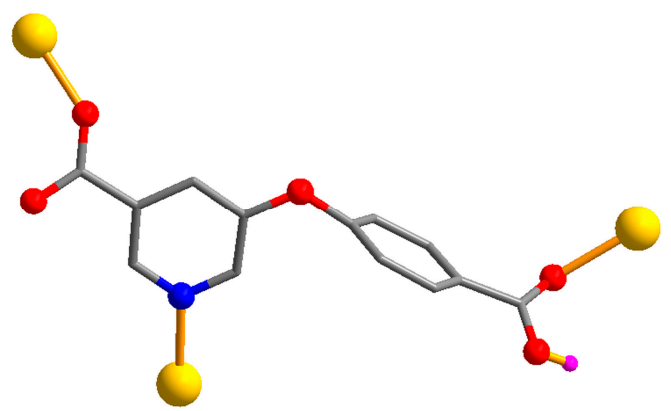

Scheme 1. The coordination mode of Hcpna- block in 1.

To better understand such intricate 3D coordination polymer structures, topological classification was carried out. Topologically, the 3D underlying net in $\mathbf{1}$ (Figure 1d) is constructed from 6-connected $\mathrm{Fe} 1$ and 3-connected $\mu_{3}-\mathrm{Hcpna}^{-}$nodes, thus disclosing a 3,6-connected binodal net of the rtl (rutile) topological type. This net can be described with a $\left(4 \cdot 6^{2}\right)_{2}\left(4^{2} \cdot 6^{10} \cdot 8^{3}\right)$ point symbol, in which the $\left(4 \cdot 6^{2}\right)$ and $\left(4^{2} \cdot 6^{10} \cdot 8^{3}\right)$ notations are those of $\mu_{3}-\mathrm{Hcpna}^{-}$and Fe1 nodes, respectively.

\subsection{TGA and PXRD}

The stability and thermal behavior of CP 1 were investigated by running TGA (thermogravimetric analysis, Figure 2a) under nitrogen atmosphere in the $20-800{ }^{\circ} \mathrm{C}$ range of temperatures. $\mathrm{CP} 1$ does not contain solvent of crystallization or $\mathrm{H}_{2} \mathrm{O}$ ligands and remains stable until $248{ }^{\circ} \mathrm{C}$; further increase of temperature leads to the decomposition of the sample.

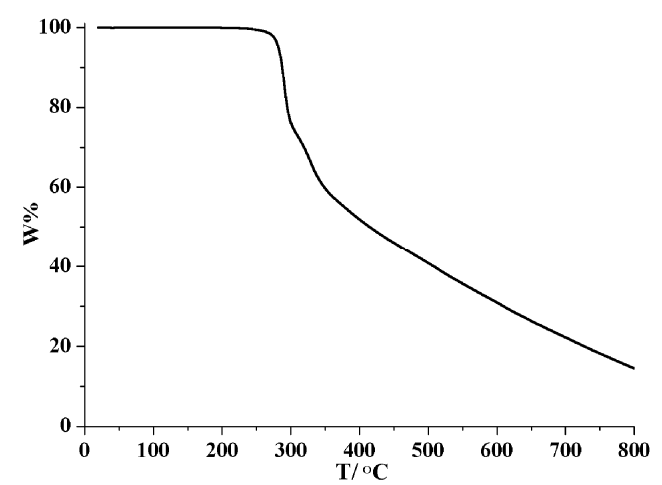

(a)

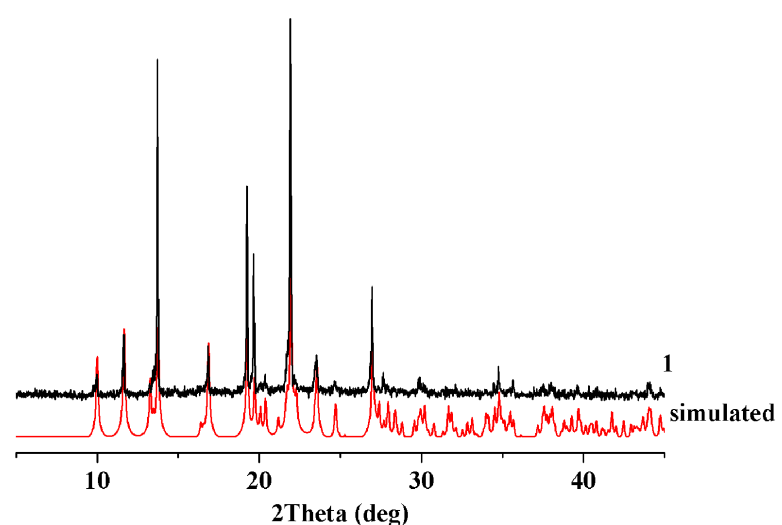

(b)

Figure 2. Thermogravimetric analysis (TGA) curve (a) and powder X-ray diffraction (PXRD) patterns (b) of 1 .

Besides, crystalline sample of CP 1 was studied by PXRD (powder X-ray diffraction analysis) and an experimental PXRD pattern of the bulk product is shown in Figure $2 \mathrm{~b}$. Comparison of the experimental pattern with that calculated from single-crystal X-ray diffraction confirms the presence of a single pure phase in the sample of $\mathbf{1}$. Moreover, elemental analysis corroborates an analytical purity of this coordination polymer.

\subsection{Catalytic Functionalization of Alkanes}

Following our continuous interest in developing different metal-complex-catalysts and protocols for oxidative functionalization of saturated hydrocarbons under mild conditions [37-40], we explored a catalytic potential of $\mathbf{1}$ in oxidation of cyclic $\mathrm{C}_{5}-\mathrm{C}_{8}$ alkanes and propane to give the respective alcohol and ketone products. Cyclohexane was investigated as a model substrate and the reactions were performed at $50{ }^{\circ} \mathrm{C}$ with hydrogen peroxide as oxidant $\left(50 \%\right.$ in water) in $\mathrm{CH}_{3} \mathrm{CN} / \mathrm{H}_{2} \mathrm{O}$ medium and using a slight amount of acid as a promoter. 
The use of $\mathrm{CH}_{3} \mathrm{CN}$ as a solvent is important for solubilization of an alkane and catalyst since the oxidation reactions practically do not undergo in only $\mathrm{H}_{2} \mathrm{O}$ as a solvent. Selection of acetonitrile can be justified by the following factors: (i) miscibility of $\mathrm{CH}_{3} \mathrm{CN}$ with $\mathrm{H}_{2} \mathrm{O}$ and aqueous $\mathrm{H}_{2} \mathrm{O}_{2}$, (ii) sufficient solubility of alkanes in $\mathrm{CH}_{3} \mathrm{CN}$, (iii) good stability of acetonitrile in the reaction medium, and (iv) good prior results for oxidative functionalization of alkanes obtained when using $\mathrm{CH}_{3} \mathrm{CN}$ as a solvent of choice [37-44].

It should be mentioned that the CP $\mathbf{1}$ is not intact during catalytic experiments and acts as a precursor of homogeneous catalytically active species. These form upon dissolution of $\mathbf{1}$ in the presence of oxidant and acid promoter. Cyclohexane oxidation to cyclohexanone and cyclohexanol does not occur without catalyst 1 (Figure 3), either in the absence or in the presence of acid promoter. In the presence of $\mathbf{1}$, the oxidation of $\mathrm{C}_{6} \mathrm{H}_{12}$ undergoes very slowly unless an acid promoter is added (Figure 3). However, an addition of TFA (trifluoroacetic acid; commonly used for promoting the activity of various $\mathrm{Cu}$ and Fe based catalytic systems [37-39]) causes a drastic acceleration of reaction rate and higher quantity of products generated ( $8 \%$ yield after $90 \mathrm{~min}$ of the reaction). The presence of PCA (2-pyrazinecarboxylic acid) in a very low amount (molar ratio PCA:1 = 3:1) results in higher catalytic activity ( $15 \%$ total product yield after $90 \mathrm{~min}$, Figure 3$)$. It should be mentioned that PCA is a recognized and powerful promoter in different metal-catalyzed oxidations of hydrocarbons [41].

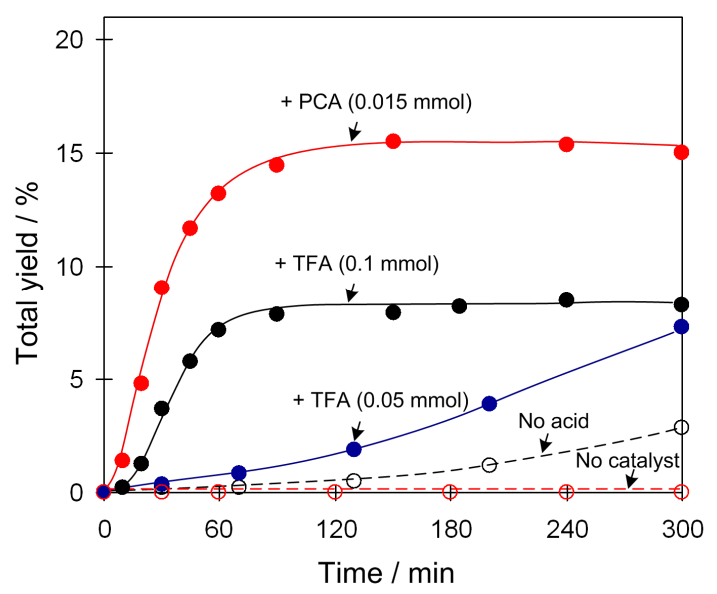

Figure 3. Influence of acid promoter on $\mathrm{C}_{6} \mathrm{H}_{12}$ oxidation by hydrogen peroxide to a mixture of cyclohexanone and cyclohexanol (total product yield vs. reaction time) catalysed by 1 . Conditions: $1(0.005 \mathrm{mmol}), \mathrm{C}_{6} \mathrm{H}_{12}(1.0 \mathrm{mmol}), \mathrm{H}_{2} \mathrm{O}_{2}\left(5.0 \mathrm{mmol}, 50 \%\right.$ in $\left.\mathrm{H}_{2} \mathrm{O}\right), 2$-pyrazinecarboxylic acid (PCA, $0.015 \mathrm{mmol}$ ) or trifluoroacetic acid (TFA, $0.05-0.10 \mathrm{mmol}$ ), $\mathrm{CH}_{3} \mathrm{CN}$ (solvent added up to $2.5 \mathrm{~mL}$ of total volume of the reaction), $50{ }^{\circ} \mathrm{C}$. Blank tests without catalyst precursor $\mathbf{1}$ (curve: no catalyst; in the presence of TFA, $0.1 \mathrm{mmol}$ ) or acid promoter (curve: no acid, in the presence of $1 ; 0.005 \mathrm{mmol}$ ) are given for comparison.

Other cycloalkanes also undergo oxidation with $\mathrm{H}_{2} \mathrm{O}_{2}$ in the presence of catalyst $\mathbf{1}$ and PCA promoter (Figure 4). In particular, the oxidation of cycloheptane (to cycloheptanol and cycloheptanone) and cyclooctane (to cyclooctanol and cyclooctanone) proceeds more efficiently (total product yield up to $22 \%$ ) than that of cyclohexane and cyclopentane. 


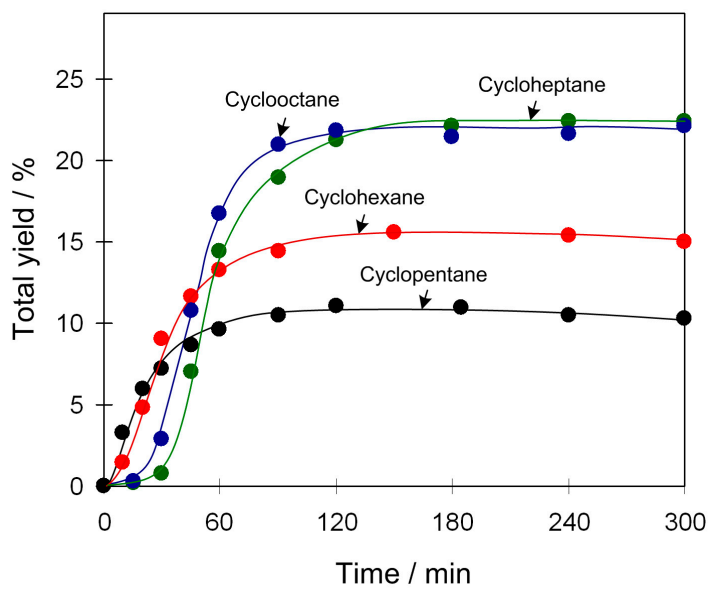

Figure 4. Substrate scope in oxidation of cyclic $\mathrm{C}_{5}-\mathrm{C}_{8}$ alkanes with $\mathrm{H}_{2} \mathrm{O}_{2}$ to corresponding ketones and alcohols (total product yield vs. reaction time) catalyzed by $\mathbf{1}$. Conditions: $\mathbf{1}(0.005 \mathrm{mmol})$, $\mathrm{C}_{5} \mathrm{H}_{10}-\mathrm{C}_{8} \mathrm{H}_{16}(1.0 \mathrm{mmol}), \mathrm{H}_{2} \mathrm{O}_{2}\left(50 \%\right.$ in $\left.\mathrm{H}_{2} \mathrm{O}, 5.0 \mathrm{mmol}\right), \mathrm{PCA}(0.015 \mathrm{mmol}), \mathrm{CH}_{3} \mathrm{CN}$ (solvent added up to $2.5 \mathrm{~mL}$ of total volume of the reaction), $50{ }^{\circ} \mathrm{C}$.

Upon addition of PCA, compound $\mathbf{1}$ also efficiently catalyses the oxidation of a light gaseous alkane such as propane (Table 2) to give a mixture of $i$-propanol, acetone, $n$-propanol, and propanal with a total product yield of $22 \%$ (based on $\mathrm{C}_{3} \mathrm{H}_{8}$ ). However, if TFA is used as a promoter, the reaction is less efficient (total product yield of 7.3\%). It should be highlighted that the product yield of up to $22 \%$ (based on propane) obtained herein is remarkable, especially if taking into account a very high inertness of this gaseous hydrocarbon along with rather mild conditions applied for running the oxidation reaction [37-41].

Table 2. Mild oxidation of propane with $\mathrm{H}_{2} \mathrm{O}_{2}$ catalyzed by $\mathbf{1}^{\mathrm{a}}$.

\begin{tabular}{cccccc}
\hline \multirow{2}{*}{ Catalyst } & \multicolumn{5}{c}{ Product Yield (\%) $\mathbf{~}^{\mathbf{b}}$} \\
\cline { 2 - 6 } & $\boldsymbol{i}$-Propanol & Acetone & $\boldsymbol{n}$-Propanol & Propanal & Total \\
\hline 1/PCA & 6.1 & 11.3 & 3.0 & 1.6 & 22.0 \\
1/TFA & 2.1 & 2.3 & 1.5 & 1.4 & 7.3 \\
\hline
\end{tabular}

${ }^{a}$ Conditions: 1 (0.005 mmol), PCA (0.015 mmol) or TFA (0.1 mmol), $\mathrm{C}_{3} \mathrm{H}_{8}(1 \mathrm{~atm}, 0.7 \mathrm{mmol}), \mathrm{H}_{2} \mathrm{O}_{2}\left(50 \%\right.$ in $\mathrm{H}_{2} \mathrm{O}, 5.0$ $\mathrm{mmol}), \mathrm{CH}_{3} \mathrm{CN}$ (solvent added up to $2.5 \mathrm{~mL}$ of total volume of the reaction), $50^{\circ} \mathrm{C}, 4 \mathrm{~h}$ in a stainless-steel reactor $(20$ mL capacity). ${ }^{\text {b. }}$ Yields based on $\mathrm{C}_{3} \mathrm{H}_{8}$ substrate: (moles of products/moles of $\mathrm{C}_{3} \mathrm{H}_{8}$ ) $\times 100 \%$.

In addition, compound $\mathbf{1}$ was evaluated as catalyst precursor in the carboxylation of cyclic $\mathrm{C}_{\mathrm{n}}$ $(n=5-8)$ alkanes and propane in the presence of $\mathrm{CO}$ (carbonyl source), $\mathrm{H}_{2} \mathrm{O}$ (hydroxyl source) and $\mathrm{K}_{2} \mathrm{~S}_{2} \mathrm{O}_{8}$ (oxidant and radical initiator) [42-44]. These carboxylations undergo in $\mathrm{H}_{2} \mathrm{O} / \mathrm{CH}_{3} \mathrm{CN}$ at $60{ }^{\circ} \mathrm{C}$ and result in generation of the respective $\mathrm{C}_{n+1}$ carboxylic acids (main products, Table 3 ). The oxidation $\mathrm{C}_{\mathrm{n}}$ products (e.g., cyclic ketones and alcohols) are also formed due to competing oxidation reactions, especially when using cyloheptane and cyclooctane as substrates. 
Table 3. Single-pot carboxylation of cycloalkanes catalyzed by $\mathbf{1}^{\mathrm{a}}$.

\begin{tabular}{lcccc}
\hline \multirow{2}{*}{ Substrate } & \multicolumn{4}{c}{ Yield (\%) $)^{\mathbf{b}}$} \\
\cline { 2 - 5 } & Cycloalkane-Carboxylic Acid & Cyclic Ketone & Cyclic alcohol & Total \\
\hline Cyclopentane & 13.9 & 3.4 & 1.7 & 19.0 \\
Cyclohexane & 20.9 & 1.1 & 0.6 & 22.6 \\
Cycloheptane & 9.2 & 6.5 & 2.5 & 18.2 \\
Cyclooctane & 4.8 & 7.8 & 5.9 & 18.5 \\
\hline${ }^{a}$ Conditions: $\mathbf{1}(0.01 \mathrm{mmol}), \mathrm{C}_{5} \mathrm{H}_{10}-\mathrm{C}_{8} \mathrm{H}_{16}(1 \mathrm{mmol}), \mathrm{CO}(20 \mathrm{~atm}), \mathrm{K}_{2} \mathrm{~S}_{2} \mathrm{O}_{8}(1.5 \mathrm{mmol}), \mathrm{CH}_{3} \mathrm{CN}(4 \mathrm{~mL}) / \mathrm{H}_{2} \mathrm{O}$ \\
$(2 \mathrm{~mL}), 60^{\circ} \mathrm{C}, 4 \mathrm{~h}$ in a stainless-steel reactor $\left(20 \mathrm{~mL}\right.$ capacity). ${ }^{\mathrm{b}}$ Yields based on cycloalkane substrate: $(\mathrm{moles}$ of \\
products/moles of cycloalkane $) \times 100 \%$.
\end{tabular}

Among the cycloalkane substrates tested, more elevated yields of carboxylic acid products are obtained in cyclohexane carboxylation $\left(21 \%\right.$ of $\left.\mathrm{C}_{6} \mathrm{H}_{11} \mathrm{COOH}\right)$ and cyclopentane carboxylation (14\% $\left.\mathrm{C}_{5} \mathrm{H}_{9} \mathrm{COOH}\right)$. Interestingly, the transformations of cycloheptane and cyclooctane result in lower yields of carboxylic acids (5-9\%) but higher yields of ketones and alcohols, while the total yields of products in all systems are in the $18-23 \%$ range. The carboxylation of propane generates $i$-butyric acid $(13.6 \%$ yield; main product) and $n$-butyric acid (3.8\% yield; minor product) owing to two types of $C$ atoms in $\mathrm{C}_{3} \mathrm{H}_{8}$ molecule.

Taking into account the mechanistic considerations from the related oxidation and carboxylation processes catalysed by various coordination compounds [37-44], we can propose the free radical pathways for the reactions studied in the present work (Figure 5). In both alkane oxidation and carboxylation reactions, compound $\mathbf{1}$ acts as a precursor of homogeneous Fe-cpna species when reacting with oxidant and/or acid promoter; these species are formed upon partial protonation of some carboxylate groups and ligand decoordination. In fact, the catalyst precursor facilitates the formation of active oxidizing species (i.e., hydroxyl radicals from $\mathrm{H}_{2} \mathrm{O}_{2}$ in alkane oxidation or sulfate radical anions from $\mathrm{K}_{2} \mathrm{~S}_{2} \mathrm{O}_{8}$ in alkane carboxylation) and eventually participates in other mechanistic steps (Figure 5).

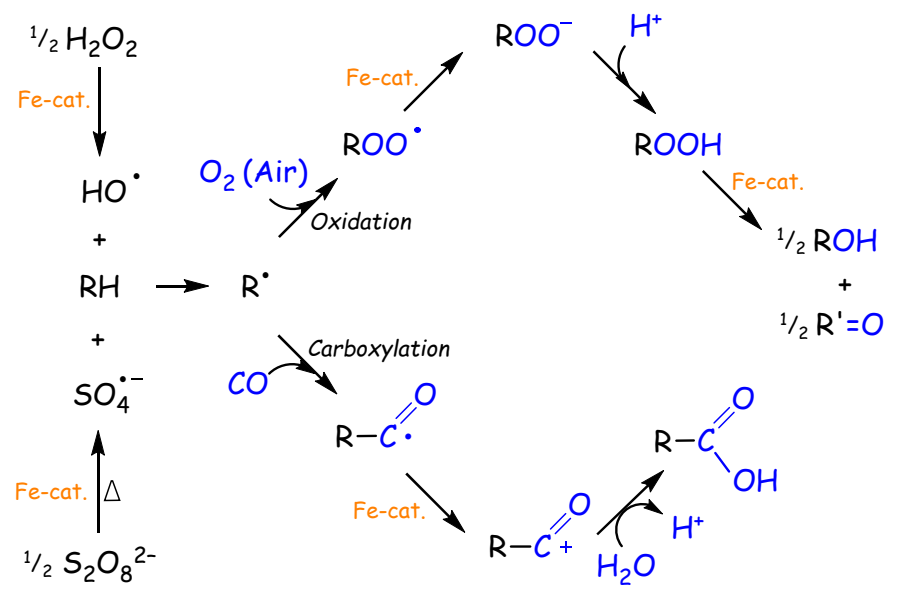

Figure 5. Simplified mechanism for oxidation and carboxylation of alkanes.

Hence, in alkane oxidation, the substrate molecules (RH) are activated by $\mathrm{HO} \bullet$ to produce alkyl radicals $\left(R^{\bullet}\right)$. These are coupled with dioxygen (present in air or generated from hydrogen peroxide) to furnish alkyl peroxo radicals $\left(\mathrm{ROO}^{\bullet}\right)$ that are further converted, via $\mathrm{ROO}^{-}$, to alkyl hydroperoxides $(\mathrm{ROOH})$ as intermediate products. In fact, the formation of $\mathrm{ROOH}$ was corroborated by performing the duplicate GC tests for selected reaction mixtures (Shul'pin's method), namely by analyzing them after and before treating with $\mathrm{PPh}_{3}[45,46]$. $\mathrm{ROOH}$ are not very stable under the reaction conditions and undergo decomposition (can also be iron-catalyzed) to generate $\mathrm{ROH}$ and $\mathrm{R}^{\prime}=\mathrm{O}$ as final alkane oxidation products $[37,42]$. 
In carboxylation of saturated hydrocarbons, $\mathrm{RH}$ react with $\mathrm{SO}_{4}{ }^{-}$as active oxidizing species to form $\mathrm{R}^{\bullet}$. Alkyl radicals are carboxylated by $\mathrm{CO}$ to give acyl radicals $\left(\mathrm{RCO}^{\bullet}\right)$ and then acyl cations $\left(\mathrm{RCO}^{+}\right)$. These are prone to undergo hydrolysis by $\mathrm{H}_{2} \mathrm{O}$ to generate carboxylic acids ( $\left.\mathrm{RCOOH}\right)$ as principal products (Figure 5). Competitive oxidation of $\mathrm{R}^{\bullet}$ to form $\mathrm{ROH}$ and $\mathrm{R}^{\prime}=\mathrm{O}$ as by-products is also observed in the present type of carboxylation processes [42-44].

\section{Conclusions}

This work described a facile hydrothermal generation and full characterization of the new Fe(II) 3D coordination polymer derived from 5-(4'-carboxyphenoxy)nicotinic acid $\left(\mathrm{H}_{2} \mathrm{cpna}\right)$ as a multifunctional organic building block. The obtained product 1 reveals the first structurally characterized Fe(II) compound assembled from $\mathrm{H}_{2}$ cpna [47].

The structure and topology of this iron 3D CP were established and discussed, revealing a 3,6-connected underlying network of the rtl topological type. Compound $\mathbf{1}$ also functions as active catalyst precursor for the homogeneous oxidation and carboxylation of propane and cycloalkanes under mild conditions, leading to up to $23 \%$ yields of products (based on alkane substrate). These values of yields are excellent considering a particular inertness of saturated hydrocarbons (especially propane) and mild conditions of the reactions studied [48-50]. For example, a related industrial process of cyclohexane oxidation to cyclohexanone and cyclohexanol (DuPont process with a homogeneous Co naphthenate catalyst) shows only $5-10 \%$ substrate conversions $[51,52]$ and proceeds under harsher reaction conditions (10-15 atm pressure, $150{ }^{\circ} \mathrm{C}$, air oxidant).

Although the present homogeneous catalytic systems derived from 1 still cannot be recycled, we believe future research aiming at trapping 1 or its soluble derivatives on solid supports might result in the development of reusable heterogeneous catalysts for alkane functionalization. Furthermore, further studies on exploring $\mathrm{H}_{2}$ cpna and related multifunctional building blocks for the hydrothermal design of new metal-organic architectures will be continued in our laboratories.

Supplementary Materials: The following are available online at http://www.mdpi.com/2073-4352/9/7/369/s1, Figure S1: ellipsoid plot of 1, Figures S2 and S3: FT-IR spectra, Figure S4: additional PXRD patterns and discussion, Figures S5 and S6: UV-vis spectra, Tables S1 and S2: selected bonding and H-bonding parameters for 1.

Author Contributions: Conceptualization, J.G. and A.M.K.; data curation, N.Z., Y.L., and M.V.K.; funding acquisition, Y.L., J.G., and A.M.K.; investigation, N.Z., Y.L., J.G., and M.V.K.; methodology, M.V.K.; visualization, J.G. and A.M.K.; writing—original draft, Y.L., J.G, M.V.K., and A.M.K.; writing—review and editing, A.M.K.

Acknowledgments: This work was supported by Guangdong Province Higher Vocational Colleges \& Schools Pearl River Scholar Funded Scheme $(2015,2018)$, Innovation Team Project on University of Guangdong Province of P. R. China (2017GKCXTD001), Science and Technology Planning Project of Guangzhou (201904010381), the Foundation for Science and Technology (FCT) and Portugal 2020 (CEECIND/03708/2017, LISBOA-01-0145-FEDER-029697). The publication was also prepared with the support of the RUDN University Program 5-100.

Conflicts of Interest: The authors declare no conflict of interest.

\section{References}

1. Glover, T.G.; Mu, B. (Eds.) Gas Adsorption in Metal-Organic Frameworks: Fundamentals and Applications; CRC Press: Boca Raton, FL, USA, 2018.

2. Hashemi, L.; Morsali, A. Pillared Metal-Organic Frameworks: Properties and Applications; John Wiley \& Sons: Hoboken, NJ, USA, 2019.

3. Adil, K.; Belmabkhout, Y.; Pillai, R.S.; Cadiau, A.; Bhatt, P.M.; Assen, A.H.; Maurin, G.; Eddaoudi, M. Gas/vapour separation using ultra-microporous metal-organic frameworks: Insights into the structure/separation relationship. Chem. Soc. Rev. 2017, 46, 3402-3430. [CrossRef] [PubMed]

4. Chen, B.; Qian, G. (Eds.) Metal-Organic Frameworks for Photonics Applications; Springer: Berlin, Germany, 2014.

5. Cui, Y.J.; Yue, Y.F.; Qian, G.D.; Chen, B.L. Luminescent functional metal-organic frameworks. Chem. Rev. 2012, 112, 1126-1162. [CrossRef] [PubMed]

6. Chen, Y.Z.; Zhang, R.; Jiao, L.; Jiang, H.L. Metal-organic framework-derived porous materials for catalysis. Coord. Chem. Rev. 2018, 362, 1-23. [CrossRef] 
7. Yu, D.Y.; Li, L.B.; Wu, M.H.; Crittenden, J.C. Enhanced photocatalytic ozonation of organic pollutants using an iron-based metal-organic framework. Appl. Catal. B Environ. 2019, 251, 66-75. [CrossRef]

8. Gu, J.Z.; Wen, M.; Cai, Y.; Shi, Z.F.; Nesterov, D.S.; Kirillova, M.V.; Kirillov, A.M. Cobalt(II) coordination polymers assembled from unexplored pyridine-carboxylic acid: Structural diversity and catalytic oxidation of alcohols. Inorg. Chem. 2019, 58, 5875-5885. [CrossRef] [PubMed]

9. Jain, P.; Ramachandran, V.; Clark, R.J.; Zhou, H.D.; Toby, B.H.; Dalal, N.S.; Kroto, H.W.; Cheetham, A.K. Multiferroic behavior associated with an order-disorder hydrogen bonding transition in metal-organic frameworks (MOFs) with the perovskite $\mathrm{ABX}_{3}$ architecture. J. Am. Chem. Soc. 2009, 131, 13625-13627. [CrossRef] [PubMed]

10. Minguez, E.G.; Coronado, E. Magnetic functionalities in MOFs: From the framework to the pore. Chem. Soc. Rev. 2018, 47, 533-557. [CrossRef] [PubMed]

11. Zheng, X.; Fan, R.; Song, Y.; Wang, A.; Xing, K.; Du, X.; Wang, P.; Yang, Y. A highly sensitive turn-on ratiometric luminescent probe based on postsynthetic modification of $\mathrm{Tb}^{3+} @ \mathrm{Cu}-\mathrm{MOF}$ for $\mathrm{H}_{2} \mathrm{~S}$ detection. J. Mater. Chem. C 2017, 5, 9943-9951. [CrossRef]

12. Jaros, S.W.; Sokolnicki, J.; Wołoszyn, A.; Haukka, M.; Kirillov, A.M.; Smoleński, P. A novel 2D coordination network built from hexacopper(I)-iodide clusters and cagelike aminophosphine blocks for reversible "turn-on" sensing of aniline. J. Mater. Chem. C 2018, 6, 1670-1678. [CrossRef]

13. Mao, N.N.; Hu, P.; Yu, F.; Chen, X.; Zhuang, G.L.; Zhang, T.L.; Li, B. A series of transition metal coordination polymers based on a rigid bi-functional carboxylate-triazolate tecton. CrystEngComm 2017, 19, 4586-4594. [CrossRef]

14. Rowsell, J.L.C.; Spencer, E.C.; Eckert, J.; Howard, J.A.K.; Yaghi, O.M. Gas adsorption sites in a large-pore metal-organic framework. Science 2005, 309, 1350-1354. [CrossRef] [PubMed]

15. Fernandes, T.A.; Santos, C.I.M.; André, V.; Kłak, J.; Kirillova, M.V.; Kirillov, A.M. Copper(II) Coordination Polymers Self-assembled from Aminoalcohols and Pyromellitic Acid: Highly Active Pre-catalysts for the Mild Water-promoted Oxidation of Alkanes. Inorg. Chem. 2016, 55, 125-135. [CrossRef] [PubMed]

16. Sotnik, S.A.; Polunin, R.A.; Kiskin, M.A.; Kirillov, A.M.; Dorofeeva, V.N.; Gavrilenko, K.S.; Eremenko, I.L.; Novotortsev, V.M.; Kolotilov, S.V. Heterometallic Coordination Polymers Assembled from Trigonal Trinuclear $\mathrm{Fe}_{2} \mathrm{Ni}$-Pivalate Blocks and Polypyridine Spacers: Topological Diversity, Sorption, and Catalytic Properties. Inorg. Chem. 2015, 54, 5169-5181. [CrossRef] [PubMed]

17. Gu, J.Z.; Gao, Z.Q.; Tang, Y. $\mathrm{pH}$ and auxiliary ligand influence on the structural variations of 5(2'-carboxylphenyl) nicotate coordination polymers. Cryst. Growth Des. 2012, 12, 3312-3323. [CrossRef]

18. Dong, Y.B.; Jiang, Y.Y.; Li, J.; Ma, J.P.; Liu, F.L.; Tang, B.; Huang, R.Q.; Batten, S.R. Temperature-dependent synthesis of metal-organic frameworks based on a flexible tetradentate ligand with bidirectional coordination donors. J. Am. Chem. Soc. 2007, 129, 4520-4521. [CrossRef] [PubMed]

19. Gu, J.Z.; Cui, Y.H.; Liang, X.X.; Wu, J.; Lv, D.Y.; Kirillov, A.M. Structurally distinct metal-organicand H-bonded networks derived from 5-(6-carboxypyridin-3-yl)isophthalic acid: Coordination and template effect of 4,4'-bipyridine. Cryst. Growth Des. 2016, 16, 4658-4670. [CrossRef]

20. Jaros, S.W.; da Silva, M.F.C.G.; Florek, M.; Oliveira, M.C.; Smoleński, P.; Pombeiro, A.J.L.; Kirillov, A.M. Aliphatic dicarboxylate directed assembly of silver(I) 1,3,5-triaza-7-phosphaadamantane coordination networks: Topological versatility and antimicrobial activity. Cryst. Growth Des. 2014, 14, 5408-5417. [CrossRef]

21. Wu, W.-P.; Li, Z.-S.; Liu, B.; Liu, P.; Xi, Z.-P.; Wang, Y.-Y. Double-step $\mathrm{CO}_{2}$ sorption and guest-induced single-crystal-to-single-crystal transformation in a flexible porous framework. Dalton Trans. 2015, 44, 10141-10145. [CrossRef]

22. Liang, Y.T.; Yang, G.P.; Liu, B.; Yan, Y.T.; Xi, Z.P.; Wang, Y.Y. Four super water-stable lanthanide-organic frameworks with active uncoordinated carboxylic and pyridyl groups for selective luminescence sensing of $\mathrm{Fe}^{3+}$. Dalton Trans. 2015, 44, 13325-13330. [CrossRef]

23. Gu, J.Z.; Kirillov, A.M.; Wu, J.; Lv, D.Y.; Tang, Y.; Wu, J.C. Synthesis, structural versatility, luminescent and magnetic properties of a series of coordination polymers constructed from biphenyl-2,4,4' $4^{\prime}$-tricarboxylate and different N-donor ligands. CrystEngComm 2013, 15, 10287-10303. [CrossRef]

24. Shao, Y.L.; Cui, Y.H.; Gu, J.Z.; Wu, J.; Wang, Y.W.; Kirillov, A.M. Exploring biphenyl-2,4,4'-tricarboxylic acid as a flexible building block for the hydrothermal self-assembly of diverse metal-organic and supramolecular networks. CrystEngComm 2016, 18, 765-778. [CrossRef] 
25. Gu, J.Z.; Liang, X.X.; Cui, Y.H.; Wu, J.; Kirillov, A.M. Exploring 4-(3-carboxyphenyl)picolinic acid as a semirigid building block for the hydrothermal self-assembly of diverse metal-organic and supramolecular networks. CrystEngComm 2017, 19, 117-128. [CrossRef]

26. Gu, J.Z.; Wen, M.; Liang, X.X.; Shi, Z.; Kirillova, M.V.; Kirillov, A.M. Multifunctional aromatic carboxylic acids as versatile building blocks for hydrothermal design of coordination polymers. Crystals 2018, 8, 83. [CrossRef]

27. Gu, J.Z.; Liang, X.X.; Cai, Y.; Wu, J.; Shi, Z.F.; Kirillov, A.M. Hydrothermal assembly, structures, topologies, luminescence, and magnetism of a novel series of coordination polymers driven by a trifunctional nicotinic acid building block. Dalton Trans. 2017, 46, 10908-10925. [CrossRef]

28. Gu, J.Z.; Cai, Y.; Liang, X.X.; Wu, J.; Shi, Z.F.; Kirillov, A.M. Bringing 5-(3,4-dicarboxylphenyl)picolinic acid to crystal engineering research: Hydrothermal assembly, structural features, and photocatalytic activity of Mn, $\mathrm{Ni}, \mathrm{Cu}$, and Zn coordination polymer. CrystEngComm 2018, 20, 906-916. [CrossRef]

29. Gu, J.Z.; Cai, Y.; Qian, Z.Y.; Wen, M.; Shi, Z.F.; Lv, D.Y.; Kirillov, A.M. A new series of Co, Ni, Zn, and $\mathrm{Cd}$ metal-organic architectures driven by an unsymmetrical biphenyl-tricarboxylic acid: Hydrothermal assembly, structural features and properties. Dalton Trans. 2018, 47, 7431-7444. [CrossRef]

30. Gu, J.Z.; Cai, Y.; Wen, M.; Shi, Z.F.; Kirillov, A.M. A new series of Cd(II) metal-organic architectures driven by soft ether-bridged tricarboxylate spacers: Synthesis, structural and topological versatility, and photocatalytic properties. Dalton Trans. 2017, 46, 14327-14339. [CrossRef]

31. Sheldrick, G.M. SHELXS-97, Program for X-ray Crystal Structure Determination; University of Gottingen: Göttingen, Germany, 1997.

32. Sheldrick, G.M. SHELXL-97, Program for X-ray Crystal Structure Refinement; University of Gottingen: Göttingen, Germany, 1997.

33. Blatov, V.A. Multipurpose crystallochemical analysis with the program package TOPOS. IUCr CompComm Newsl. 2006, 7, 4-38.

34. Blatov, V.A.; Shevchenko, A.P.; Proserpio, D.M. Applied topological analysis of crystal structures with the program package ToposPro. Cryst. Growth Des. 2014, 14, 3576-3586. [CrossRef]

35. Lu, W.G.; Gu, J.Z.; Jiang, L.; Tan, M.Y.; Lu, T.B. Achiral and chiral coordination polymers containing helical chains: The chirality transfer between helical chains. Cryst. Growth Des. 2008, 8, 192-199. [CrossRef]

36. Gu, J.Z.; Gao, Z.Q. Synthesis, crystal structure, magnetic properties of a compound based on eight-coordinated iron(II) ion. Chin. J. Ionrg. Chem. 2012, 28, 1038-1042.

37. Costa, I.F.M.; Kirillova, M.V.; André, V.; Fernandes, T.A.; Kirillov, A.M. Tetracopper(II) Cores Driven by an Unexplored Trifunctional Aminoalcohol Sulfonic Acid for Mild Catalytic C-H Functionalization of Alkanes. Catalysts 2019, 9, 321. [CrossRef]

38. Dias, S.S.P.; Kirillova, M.V.; André, V.; Kłak, J.; Kirillov, A.M. New Tetracopper (II) Cubane Cores Driven by a Diamino Alcohol: Self-assembly Synthesis, Structural and Topological Features, and Magnetic and Catalytic Oxidation Properties. Inorg. Chem. 2015, 54, 5204-5212. [CrossRef]

39. Dias, S.S.P.; Kirillova, M.V.; André, V.; Kłak, J.; Kirillov, A.M. New tricopper(II) cores self-assembled from aminoalcohol biobuffers and homophthalic acid: Synthesis, structural and topological features, magnetic properties and mild catalytic oxidation of cyclic and linear $\mathrm{C}_{5}-\mathrm{C}_{8}$ alkanes. Inorg. Chem. Front. 2015, 2, 525-537. [CrossRef]

40. Fernandes, T.A.; Santos, C.I.M.; André, V.; Dias, S.S.P.; Kirillova, M.V.; Kirillov, A.M. New aqua-soluble dicopper(II) aminoalcoholate cores for mild and water-assisted catalytic oxidation of alkanes. Catal. Sci. Technol. 2016, 6, 4584-4593. [CrossRef]

41. Kirillov, A.M.; Shul'pin, G.B. Pyrazinecarboxylic acid and analogs: Highly efficient co-catalysts in the metal-complex-catalyzed oxidation of organic compounds. Coord. Chem. Rev. 2013, 257, 732-754. [CrossRef]

42. Armakola, E.; Colodrero, R.M.P.; Bazaga-García, M.; Salcedo, I.R.; Choquesillo-Lazarte, D.; Cabeza, A.; Kirillova, M.V.; Kirillov, A.M.; Demadis, K.D. Three-Component Copper-Phosphonate-Auxiliary Ligand Systems: Proton Conductors and Efficient Catalysts in Mild Oxidative Functionalization of Cycloalkanes. Inorg. Chem. 2018, 57, 10656-10666. [CrossRef]

43. Kirillova, M.V.; Kirillov, A.M.; Pombeiro, A.J.L. Metal-free and copper-promoted single-pot hydrocarboxylation of cycloalkanes to carboxylic acids in aqueous medium. Adv. Synth. Catal. 2009, 351, 2936-2948. [CrossRef] 
44. Kirillova, M.V.; Kirillov, A.M.; Pombeiro, A.J.L. Mild, single-pot hydrocarboxylation of gaseous alkanes to carboxylic acids in metal-free and copper-promoted aqueous systems. Chem. Eur. J. 2010, 16, 9485-9493. [CrossRef]

45. Shul'pin, G.B. Metal-catalyzed hydrocarbon oxygenations in solutions: The dramatic role of additives: A review. J. Mol. Catal. A Chem. 2002, 189, 39-66. [CrossRef]

46. Shul'pin, G.B. Hydrocarbon Oxygenations with Peroxides Catalyzed by Metal Compounds. Mini-Rev. Org. Chem. 2009, 6, 95-104. [CrossRef]

47. Groom, C.R.; Bruno, I.J.; Lightfoot, M.P.; Ward, S.C. The Cambridge Structural Database. Acta Cryst. 2016, B72, 171-179. [CrossRef]

48. Shilov, A.E.; Shul'pin, G.B. Activation and Catalytic Reactions of Saturated Hydrocarbons in the Presence of Metal Complexes; Kluwer Acad. Publ.: Dordrecht, The Netherlands, 2000.

49. Bäckvall, J.-E. (Ed.) Modern Oxidation Methods, 2nd ed.; John Wiley \& Sons: Hoboken, NJ, USA, 2011.

50. Shul'pin, G.B. New Trends in Oxidative Functionalization of Carbon-Hydrogen Bonds: A Review. Catalysts 2016, 6, 50. [CrossRef]

51. Hagen, J. Industrial Catalysis: A Practical Approach; John Wiley \& Sons: Hoboken, NJ, USA, 2015.

52. Schuchardt, U.; Cardoso, D.; Sercheli, R.; Pereira, R.; da Cruz, R.S.; Guerreiro, M.C.; Mandelli, D.; Spinace, E.V.; Pires, E.L. Cyclohexane Oxidation Continues to be a Challenge. Appl. Catal. A Gen. 2001, 211,1-17. [CrossRef]

(C) 2019 by the authors. Licensee MDPI, Basel, Switzerland. This article is an open access article distributed under the terms and conditions of the Creative Commons Attribution (CC BY) license (http://creativecommons.org/licenses/by/4.0/). 